ENSAYO

\title{
EL DOBLE JUEGO DE DON QUIJOTE: \\ DESREALIZACIÓN DE LA REALIDAD \\ Y REALIZACIÓN DE LO IRREAL
}

\begin{abstract}
Antonio Skármeta
Don Quijote es un personaje que al salir de sí mismo y exponerse a la aventura, provoca que las personas que encuentra en su ruta participen con él en juegos de cambio de identidad. Salir de sí mismos, aun para jugar la comedia, implica que el caballero andante saca de su rutina a la gente, y los hace conocer la libertad de saber que la "realidad" es apenas una interpretación de la realidad. A juicio del escritor chileno, don Quijote es así un hombre del Renacimiento, que disfruta y esparce la incertidumbre de haberse despedido de un mundo de creencias para entrar a otro que hay que fabricarse. En este sentido, es un verdadero vanguardista. No sólo alguien que sale corriendo al frente, sino un artista que hace correr adelante a los demás.
\end{abstract}

\section{$\mathrm{L}$}

as celebraciones ocasionadas por los 400 años del Quijote han permitido que se multipliquen visiones de esta obra fuera de los ámbitos eruditos y académicos para recoger el testimonio de su lectura y efecto en los más variados círculos.

ANTONIO SkÁRmeta es graduado de la Universidad de Chile y de Columbia University en Nueva York. Ha sido profesor de literatura hispanoamericana y filosofía en la Universidad de Chile y de literatura contemporánea y comparada en Washington University de Saint Louis, Missouri, Estados Unidos. Autor, entre otras publicaciones, de las novelas Ardiente paciencia (1985, llevada al cine como El cartero y Pablo Neruda), La boda del poeta (1999, premio Médicis 2001 a la mejor novela extranjera), La chica del trombón (2001) y El baile de la victoria (2003, premio Planeta).

Estudios Públicos, 100 (primavera 2005). 
Especialmente los escritores de distintos continentes fuimos una y otra vez invitados a disertar sobre el carácter de esta novela medular y su vigencia e interés contemporáneo, más allá del hecho indiscutido de encontrarnos ante un clásico, y, en especial, a dar testimonio de cómo sentimos personalmente esta obra, es decir cuán profunda o tangencialmente ha modelado nuestro propio trabajo creativo.

Uno de los episodios más novedosos y comunicativos entre los que participé fue la serie de televisión "Las rutas del Quijote" de la productora puertorriqueña "Entrenos", dirigida por Caridad Sorondo. Desde la idea inicial el proyecto combinaba la amplia irradiación de una obra televisiva con el análisis literario y el enfoque personal de cinco autores: Carlos Fuentes, José Saramago, Arturo Pérez Reverte, Luce López Baralt, y el mío propio, que explayé en el episodio de una hora que cerraba la serie.

Frente a la inmensidad del tema, y a la infinita bibliografía sobre él, que incluye obras maestras de crítica como la reciente El Quijote y la poética de la novela de Félix Martínez Bonati (Editorial Universitaria, Santiago de Chile, 2004), los autores embarcados en la serie preferimos privilegiar nuestra relación espontánea con el Quijote, poniendo énfasis en aquellos aspectos que más nos habían inquietado y que eventualmente seguían obrando en nuestra propia escritura u obsesiones.

Carlos Fuentes habló del Quijote como un libro situado entre el Renacimiento y la Contrarreforma, Saramago puso a prueba la eventual "locura" del hidalgo, Luce López Baralt no dudó en ver los rasgos freudianos ocultos en el amor neoplatónico de Quijote por Dulcinea, y Pérez Reverte debatió los conceptos de honor y valentía. Yo me dejé entusiasmar por el hecho nada menor de que los viajes de don Quijote, que lo abren a las más asombrosas aventuras, sean desarticulados en minuciosos retornos a la modestia de la casa y aldea que lo ve partir.

Hay cuatro puntos cardinales donde mi literatura decanta admiración por el Quijote y elabora temas y atmósferas activamente vigentes en mi literatura. Los enumero e ilustro brevemente para concentrarme luego en sólo uno de ellos:

1) En el Quijote hay un viaje de ida y de vuelta, donde el gran vuelo de la imaginación termina recogiéndose en una cotidianeidad que resulta, a la larga, mortal. Una y otra vez en mi obra narrativa he querido que la expansión lírica, orquestada dramatúrgicamente, se concentre en la modesta claridad de una experiencia compartida en la comunidad. He utilizado en mis ensayos el más gráfico y aéreo término "aterrizar" para definir el fin de mis ficciones, especialmente en las notas minimalistas de desencanto, de acep- 
tación antiheroica de la realidad, de gesto sonriente ante el heroísmo que se ha probado tan inevitable cual inútil. En las líneas siguientes los lectores de este texto verán cómo esta voluntad de estilo, que se decanta de un modo de percibir la existencia, prejuicia muy subjetivamente mi interpretación de las hazañas y fracasos del Quijote.

2) En esta novela inaugural se produce y provoca una tensión magnífica entre el discurso del hidalgo, elaborado y culto, libresco y ensoñado, y la reflexión popular, efizcamente burda, insolentemente refranera de Sancho. Esta tensión entre lo culto y lo popular mantiene el relato en la deliciosa frontera de la ironía, que, a mi modo de ver, es una de las pocas maneras por las que puede optar un narrador democrático, no autoritario, para desarrollar sus ficciones contemporáneas. Es una sustancia similar, recogida con cariñosa admiración, la que anima la relación entre Pablo Neruda y el Cartero en mi novela "El cartero de Neruda".

3) A lo largo de la novela el amor neoplatónico por Dulcinea es puesto a prueba y en peligro en distintas andanzas semieróticas que se le proponen al hidalgo, siendo la más significativa de ellas, el episodio en el palacio de los Duques, donde es tentado por la adolescente Altisidora, que en mi perspectiva detona una de las principales novelas de la modernidad. Me refiero a Lolita de Nabokov. Me siento personalmente atraído por este asunto, pues en mi novela La velocidad del amor, propongo una lectura metaliteraria de la tradición del motivo donde un hombre maduro cae seducido por una ninfeta. Mi ficción cubre desde la actualidad clásica hasta el genial libro del autor ruso, y utilizo, como en el libro de Cervantes, versos y canciones para despertar la inquietud en el amante codiciado, por burla o auténtico apetito. En La velocidad del amor, la ninfeta y tenista Sophie acomete al cincuentón Dr. Papst con el poema "La mar" de Milosz, y logra así, con versos, desequilibrarlo.

Esta actitud no es sólo una estrategia post-moderna, como algunos críticos interpretaron, pues ya aparece sabrosamente condimentada en el episodio Cuarenta y seis de la Segunda Parte, antes de que el Caballero de la Triste Figura sea asediado por dos tipos de felinos: los gatos propiamente tales, que lo despedazan, y la doña Rodríguez, temible y poco agraciada nodriza, que cae en la pieza del hidalgo como un fatal reemplazo de la adolescente Altisidora.

En la corte de la Duquesa, la presencia de don Quijote ha alborotado a todo el mundo, y la pequeña Altisidora finge un desmayo de emoción al ver pasar al hidalgo, circunstancia que aprovecha una de sus cómplices amigas para desabrochar el pecho y que Quijote pueda ver con sus propios ojos lo que Altisidora le ha contado antes en verso: 
Niña soy, pulcela tierna;

mi edad de quince no pasa:

catorce tengo y tres meses,

te juro en Dios y en mi ánima.

$*$

Oye a una triste doncella, bien crecida y mal lograda, que en la luz de tus soles se siente abrasar el alma.

Aunque don Quijote le ha endilgado a la burlona provocadora algunas consejas morales que le calmen la calentura, no es menos cierto, que por primera vez en la abundante novela, y aunque siga encomendándose a su Dulcinea para resistir las tentaciones carnales, algo especial pasa por su espíritu pues comete la insinuante travesura de fingir un estornudo (Capítulo Cuarenta y tres) para hacerles saber a las ninfetas que está en la habitación y que quiere oír las coplas amorosas que le dedican.

Love's labour's lost, pues el héroe puede jugar con la tentación, pero no sucumbir a ella. Delito que sí perfeccionó en la literatura el travieso Nabokov, y en la vida real Edgar Allan Poe casándose con su prima de trece años Virginia Clemm. Con los detritos de estas osadías yo armé un modesto puzzle intertextual cuya luminosa inventiva primigenia detecto en Cervantes.

4) Y por último estimo que la conmoción mayor conseguida de mis lecturas del Quijote derivan de una apreciación del efecto que tiene en los otros la fantasía que pone en práctica el héroe cervantino. Si don Quijote es un héroe desensimismado, su más maravillosa dote, o talento, es el de desensimismar a los demás. Con esto crea en el universo de la novela una inestabilidad óntica que es la fuente de su poderosa modernidad.

Es entonces este último tema el que prefiero hoy desarrollar para mi contribución a la revista Estudios Públicos, sabiendo que en cuanto le ponga punto final a este artículo, sucumbiré con igual entusiasmo a escribir sobre los otros asuntos que por razones editoriales ahora sólo dejé enunciados.

Sé muy bien que mirar con lente de aumento algunos elementos con los cuales uno tiene especial afinidad presenta el riesgo de desequilibrar una visión más ponderada del engranaje total de la obra y sin duda que alienta la especulación de un imaginar que se siente cómplice de las intenciones del autor, pero aprovecho esta declaración de inconvenientes para confesar que mi punto de vista es animado por cierta deliciosa característica del narrador (de los narradores) de don Quijote: a saber, la tranquila despro- 
lijidad con que las cosas suceden atenidas a diferentes lógicas narrativas, a olvidos voluntarios y reales, o astutamente irónicos. El hecho formidable de que en la primera línea el narrador decida no acordarse del lugar de donde arranca la acción, legitima el cúmulo siguiente de imprecisiones que introduce con la mayor naturalidad la fuerza espiritual que anima a esta obra: la incertidumbre. Hombre del Renacimiento, es decir dueño de su destino, Cervantes asiste al magnífico espectáculo del deterioro de una cosmogonía y de la fantástica explosión que significa el derrame de los europeos hacia infinitos territorios. "El sol no se pone jamás en su reino", va a ser la orgullosa frase de la Conquista. Pero tampoco el sol mismo es el estrella número uno de la galaxia. Esto acarrea al menos un escalofrío metafísico. Y una pizca de anarquía. Cervantes, capaz de discernir y recrear distintas temperaturas ónticas, con astuta piel de cordero somete a una práctica comediante las fantasmagorías de los libros de caballeros andantes, y al hacerlo, con gracia nada pedante ni didáctica, nos conduce a la liberadora noción de que las interpretaciones de la realidad no son la realidad, y de que esto que llamamos "lo real" es apenas una convención donde los seres viven atrapados.

La estrategia de la locura es la metáfora más clara para henchir de significación la subjetividad cuestionadora. Que el Quijote esté o no loco es un asunto sobre el cual cada lector se ha formado certezas y los eruditos han elaborado sofisticados escritos para apoyar una tesis u otra. A mí, de oficio narrador, lo que más me impresiona en la composición de la obra son los niveles de libertad, juegos de personalidad variables, que no atañen sólo al personaje central sino a la amplia gama de personajes que enfrenta, y que confronta, de quienes, admito, es víctima, pero al mismo tiempo, su maravilloso manipulador de hilos.

Es regocijante que don Quijote, que en la estrategia del narrador y del solidario lector luce loco, declare en variadas ocasiones que si las cosas siguen así de mal, podría "volverse” loco. ¡Caramba!

En el Capítulo Veinticinco sin que nada lo apremie anuncia que hará penitencia realizando algunas "locuras melancólicas". Y, ¡atención!, proclama que si estas locurillas teatrales no tienen el efecto deseado sobre Dulcinea, entonces sí teme - textual- "volverse loco de veras".

Que el hidalgo tenga tan dramatúrgica noción de niveles de locura - y por tanto comprensión de las diferencias en los estratos de realidadhace que en al menos en uno de ellos tenga una especial lucidez: cuando testigo de los infortunios de Cardenio lo define como "desdichado loco".

La táctica de la locura - si admitimos que en ella hay capas de diferentes valencias - conduce a la parábola de una existencia cuestionadora y 
deseable - cuyo objetivo estratégico es la desrealización de lo real y su genial contraparte, a saber, la realización de la irrealidad.

Si probamos que éste es el sistema circulatorio de don Quijote, ¿cómo podríamos extrañarnos que a nuestros narradores coetáneos, duchos en técnicas desrealizadoras y en el culto al irrealismo, el colega Cervantes no les resulte un cabal compañero de ruta?

El lugar común que se asocia con la modernidad es el suspiro de Rimbaud "Yo es otro". Procesos de otredad, de ensimismamiento en roles, y de desensimismamientos de existencias precarias para construir modelos épicos o pastoriles que exceden las modestas fronteras rutinarias, constituyen consecuentemente el itinerario de don Quijote.

Destaco a modo de ejemplo situaciones que los lectores de la obra pueden completar con su propia experiencia. A lo largo de su trayecto las personas que el hidalgo encuentra asumen papeles, roles, disfraces, y una secreta alegría de ser-otro brota en cada uno de ellos. Es cierto que el Caballero de la Triste Figura recibe de estas puestas en escena palizas al por mayor y que una cuarta parte de ellas hubiera bastado - en un plan realista- para llevarlo a la sepultura.

Pero no son estos accidentes de tránsito, tan innumerables como crueles, los que lo matan, sino el juego de estar de vuelta en casa, con el irónico remate donde el loco declara estar cuerdo. Esta cordura sí que es mortal, y en contraste, las demencias superadas aparecen ahora como salvoconductos a la vida, mejor aún como aperturas a la sobrevida, es el sentido preciso de más vida.

Se ha querido ver en la muerte del hidalgo un nostálgico homenaje al fracaso, al fin de los sueños, un apocalipsis de desilusión, el ejercicio activo del desvanecimiento de la magia, en fin, la consagración de la derrota.

Aun admitiendo que los episodios finales de la novela, desde la visita a las casas de los Duques hasta el retorno a la aldea, muestran un Quijote con muy existenciales dudas y una vocación de desarticular su personaje, este proceso habría que contrastarlo con el juicio de los testigos más inmediatos de su claudicación.

Para empezar me llama la atención esa sutileza a la Séneca del mismísimo Sancho Panza — que ahora transita del refranero popular a los clásicos latinos - cuando llegan a su aldea: "recibe también a tu hijo don Quijote, que, si viene vencido de los brazos ajenos, viene vencedor de sí mismo". La pregunta que cabe hacer aquí, es qué quiere decir Sancho, el más privilegiado testigo, y doble de don Quijote. En efecto, el rústico asume casi tantos roles como su amo. Se puede afirmar así que el transformismo es ya hábito y elemento definitorio de su carácter. Su sentencia está en plena sintonía con 
el epitafio al caballero del letrado bachiller Sansón Carrasco: "Yace aquí el hidalgo fuerte, que a tanto estremo llegó de valiente, que se advierte que la muerte no triunfó de su vida, con su muerte".

Vencer, triunfar.

Si los epitafios son síntesis de una vida, la última posibilidad de acotar al difunto en una fórmula, tenemos que admitir que la pequeña comunidad "culta", "letrada" y "familiar" que rodea a don Quijote acierta con ellos. Al endigarle estas dos sentencias estremecedoras, que son decantadas del noble proceso de crecimiento del héroe, los villanos revelan una comprensión cabal de su grandeza.

Que ésta no es meramente retórica se prueba en el significativo número de acciones y propuestas que ellos elaboran para mantener a don Quijote como ente fantástico.

El "triunfo" no es, polemizo, la recuperación de la cordura, pues esta sí lo mata, ni la sangrienta autoironía con que el "loco" declara que en los nidos de antaño no hay pájaros hogaño, ni la consecuente frase "yo fui loco y ya soy cuerdo", ni la servil súplica de que se le "vuelva la estimación que de él se tenía" antes de emprender sus salidas.

El "triunfo" es en segunda instancia la galería de seres que fugazmente desensismó para gloria del juego, del teatro, y de la apertura significativa a una visión anárquica y nihilista de la realidad, pero en primerísimo lugar el fervoroso programa de sus más carnales amigos de transformarse todos ellos ahora en personajes de novela pastoril: a la primera indicación de que don Quijote podría llamarse ahora "Quijotiz", Sansón "pastor Carrascón", el cura "Curiambro" y Sancho "Pancino", el mismo Sansón Carrasco incurre en una retahíla de nombres probables para todas las dulces pastoras que encuentren en la senda: Fílidas, Amarilis, Dianas, Fléridas, Galateas, Belisardas. Y hasta Teresa Panza pasaría a ser "Teresaina".

En el ya mencionado El Quijote y la poética de la novela, Martínez Bonati hace decantar su prodigiosa erudición sobre esta obra en aquello que quizás sea su encanto más inasible, y para el cual encuentra sin embargo un término preciso. En efecto, afirma que el gesto cervantino fundamental es una indibujable sonrisa (p. 128).

Así, intuye con comunicativa convicción que estamos en vida y obra asistiendo a una afirmación a la vez melancólica y gozosa de la existencia, y a la paradoja de un desengañado feliz:

Pues nuestro loco se nos ha tornado ya simpático, y hasta admirable, antes de su reconversión a la salud habitual. La caballería le ha mostrado (y nos ha mostrado) valores y metas impracticables así, pero no falsos. 
El retorno a la salud, no es pues pura alegría y perfección, sino también pérdida, melancolía, resignación.

La "estimación que de él se tenía" no puede leerse sino como un grado sumo de melancólica autoironía, pues el modesto aprecio anterior de la aldea, rutinario y pobretón, es absolutamente incomparable con el prestigio que don Quijote suscita en todas las vidas que ha movido a lo largo de su hazañas a quienes a través del juego de cambio de identidades los ha dejado encaminados en la libertad de imaginarse otros. Más significativo aún es el hecho que la ficción desborda sus propios límites y contagia la literatura y la vida. En la Segunda Parte, don Quijote y Sancho ya son personajes de otras obras, y en la reciente The Cambridge History of Spanish Literature (2004), la grandiosa empresa de David. T. Gies, el académico Anthony Close nos informa que el éxito de la Primera Parte de Don Quijote había sido tan instantáneo que en el mismo año de su publicación, 1605, "Don Quijote and Sancho appeared as carnival figures in public festivities held in Valladolid, and, from henceforth, would pass into Spanish, then universal, folklore".

Tan significativo como esto es que el reconocimiento y fama afirma la voluntad escritural de Cervantes quien, así estimulado, se mantiene febrilmente creador hasta su muerte.

Si tras la lectura de la Primera Parte el pueblo encarna a sus héroes como personajes de carnaval, probablemente al final de la Segunda Parte la pareja convive en el alma de los lectores en una dimensión más entrañable. Los epitafios o meditaciones mortuorias de la Segunda Parte son ingeniosas, pero no dudan de la nobleza del hidalgo.

Compárense estos epitafios con los belicosamente farsescos del fin de la Primera Parte, escritos por los académicos de Argamasilla, donde la burla no se matiza con el afecto ni a don Quijote, ni a Sancho, ni a Dulcinea, y hasta el pobre Rocinante recibe palos, esta vez "poéticos":

Aqui yace el caballero

bien molido y malandante

a quien llevó Rocinante

por uno y otro sendero.

Sancho Panza el majadero

yace también junto a él,

escudero el más fiel

que vio trato de escudero.

La vuelta de don Quijote, sus vueltas, es preciso leerlas como parte de la noble y amatoria tensión que hay en toda la novela entre aventura y 
terruño, subcapítulo fundamental del diapasón mayor entre gran cultura y cultura popular. El libro mantiene el delicioso equilibrio entre ambas, y es este delicado balanceo el esqueleto de su grandeza y complejidad. Las personas que don Quijote va encontrando, y que gracias a su virtuosa fantasía se transforman en personajes, son seres "realistas", es decir, figuras que llevan en sí una carga de realidad nunca del todo desvirtuada por el rol que asumen. Así como el hidalgo inventa su neoplatónico amor con una robusta mozuela de la villa con quien ni siquiera ha cambiado palabra, todos los otros protagonistas, aun los más hostiles, reciben del autor la imagen acuñada en un concepto territorial, acotada en sentimientos de pertenencia a un terruño, nada comparable con las pintura deformadas de gran parte de los libros de caballería.

Así como el tono emocional del fin de la Segunda Parte y término de la novela difiere del de la primera sección, el amor a la aldea circunscrita como señal de identidad y entramado de afectos, arroja una cálida luz sobre la calidad emocional de la fantasía dramatúrgica, lírica y narrativa de España. Es con una rústica alforja que se parte de viaje, y las maravillas del mundo, se traen de vuelta a ese reducto. Es don Quijote de La Mancha (marquemos ahora con énfasis el lugar), el que va y vuelve. Va desde sus experiencias íntimas y próximas, desde sus lecturas y amistades, desde sus anhelos, y vuelve con la modestia desganada que le atribuye el narrador a ese lugar del cual "no quiere" acordarse, pero en el cual aterriza, fiel a una vocación grupal, el más aventurero de sus hijos.

La inmensa decisión hay que comprenderla en el movedizo contexto de la vida de Cervantes y la de la prodigiosa aventura de España, desbordándose hacia el mundo entero detrás de oros y quimeras sin límites. Es esta circunstancia la que afina la rural voz del protagonista de El villano en su rincón, de Lope de Vega, cuando se subleva frente a la ambición desmesurada de los hombres, sus fantasías hiperbólicas, y hace una variante más agresiva del motivo tradicional del elogio de aldea y desprecio de cortes. La oposición ahora se amplía y es entre terruño y universo, el espacio de los conquistadores. Las palabras de Nuño, en la sexta escena del primer acto:

Ríome del soldado,

que, como si tuviese

mil piernas y mil brazos, va a perdellos;

$y$ el otro desdichado,

que, como si no hubiese

bastante tierra, asiendo los cabellos

a la fortuna, y dellos 


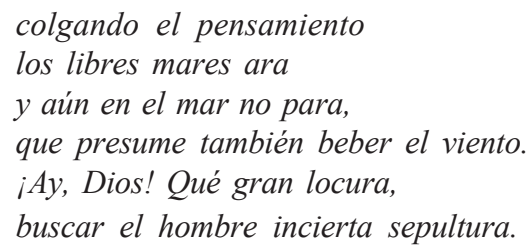

Mucho de este tono estoico, y aun con mayor sarcasmo se encuentra en las Kenningar islandesas que Borges disfrutaba tanto; por ejemplo aquella que define al guerrero como "festín del buitre" o "delicia de los cuervos", o "teñidor de espadas" ("Las Kenningar", en Historia de la eternidad, Obras completas de Jorge Luis Borges, 1923-1949, Volumen 1, Buenos Aires, Emecé Editores, octubre de 1994).

En los momentos en que los españoles salen al mundo, estos descubren también otra inmensidad en sí mismos. Hemos señalado la disposición de los próximos a don Quijote para transformarse en pastores, y aunque destaco esta situación justo porque está al final del libro, esto no significa que a lo largo de toda la obra no haya personas que tienen ocupaciones muy serias y cabales que no se desdoblen en un juego, sean duques o fonderos, para entrar al campo fantástico del hidalgo. Cierto que en el palacio de la Duquesa, como en la mayoría de los episodios, los personajes asumen roles para ejercer una forma degradada y degradante de conducta: la burla. Pero las artimañas del complot rinden proezas inesperadas: Sancho, gobernador, resulta de una lucidez apabullante. Que el rústico, alzado por virtud del juego a la altura de autoridad de una ínsula, se supere sublimemente, es uno de los capítulos más subversivos de la novela.

Quisiera valerme de un extrapolación de los conceptos de Ortega y Gasset en Meditaciones del Quijote para proponer una imagen aun más gráfica de lo que intento expresar. Al referirse al aspecto "hermetismo" del género novelesco, señala que esta virtud es la mayor del género:

¡Sublime, benigno poder que multiplica nuestra existencia, que nos liberta y pluraliza, que nos enriquece con generosas transmigraciones ( $\mathrm{Me}$ ditaciones del Quijote, Madrid, Revista de Occidente, 1963, p. 179.)

Que el mayor adalid de la filosofía vitalista dentro del pensamiento contemporáneo acuda a la novela para definirla como un género liberador por su capacidad multiplicadora de vida, y que dedique su tratado nada menos que al Quijote, combina de maravillas con su idea central de que el "hombre es el animal fantástico".

Juguemos por un instante a trasladar las características del género, y apliquémoselas al héroe. Veremos entonces que gran cantidad de personas 
están inspiradas, o provocadas, por don Quijote, dispuestas a salir de sí aunque sea momentáneamente para cumplir con un rol que por un momento les parece más divertido que el rutinario ser que cargan y los define.

Inventarse un ser.

"Poéticamente habita el hombre" sentenciaba el brillante y magnífico loco Hölderlin, y no quería decir en primer lugar que lo hiciera escribiendo poesía, sino haciéndose a sí mismo, inventándose su ser. Es la muy material palabra griega "poiesis", "producción" la que está en juego. Producirse, por tanto.

¿No es ésta la gloria mayor del Renacimiento? ¿No puedo acaso intentar ser lo que se me ocurra porque se desarticuló el horizonte de convicciones y creencias? No cabe duda que la Contrarreforma está a la vuelta de la esquina con sus feroces bastones dispuestos a golpear a los chiquilines traviesos que han subvertido la rigidez del dogma y que la represión a las fantasías alternativas lleva a muchos pensadores originales a la hoguera.

Se ha desencadenado en toda la novela $y$ en el mundo real que lo aprueba con guiños jubilosos, el arte del histrionismo. Un juego peligroso, como lo ha indicado con quirúrgica precisión Albert Camus en su capítulo "La comedia" de El mito de Sísifo.

Pero mucho antes el Premio Nobel francés había expresado algo rotundo e incisivo: "Con respecto a todos los problemas esenciales, y considero como tales a los que ponen en peligro la vida o los que decuplican el ansia de vivir, no hay probablemente sino dos métodos de pensamiento: el de Pero Grullo y el de don Quijote. El equilibrio de evidencia y lirismo es el único que puede permitirnos asentir al mismo tiempo a la emoción y a la claridad".

Es extremadamente consecuente con esta intuición en la cual liga a don Quijote que Camus dedicara al actor, a la profesión de actuar, uno de los segmentos más apasionantes de su famoso libro. Como buen lector de Nietszche, Camus comprende que lo que importa no es la vida eterna, sino la eterna vivacidad.

Y que esto era grave en la Contrarreforma, y en los siglos siguientes, lo sabían mejor que nadie los comediantes, quienes estaban excomulgados de antemano: "Ingresar en la profesión era elegir el infierno. Y la Iglesia los consideraba como sus peores enemigos. Algunos literatos se indignan: "¡Cómo, negar a Molière los últimos sacramentos!"

Américo Castro, en Pensamiento de Cervantes, estaba con su erudición bastante cerca de lo que Camus rodea, apuntando a otro registro de su filosofía del absurdo, a saber, que "Cervantes fue un gran disimulador que 
cubrió de ironía y habilidad opiniones e ideas contrarias a las usuales" (Barcelona: Noguer, 1980).

Camus detecta en el arte del actor la verdad fecunda de que no hay frontera entre lo que un hombre quiere ser y lo que es. Alonso Quijano crea un medium, un saltimbanqui partero de almas: en primer lugar de sí mismo, y en él permanece amatoriamente posesionado hasta el melancólico final de la figura que crea. Figura activa, porque don Quijote participa en el mundo y no en los recovecos de la esquizofrenia ni en la intimidad de una pieza en su aldea. El juega "para todos". Y cuando se ha extenuado en su comedia (Camus: "Hay casas de retiro para los comediantes viejos") sucumbe a un cuerpo paródico que le pide la dignidad del Pero Grullo. No es la otredad la que le trae la muerte, sino el ensimismamiento del fin. Lo mata la melancolía del fracaso, dicen muchos. Quiero insinuar una discrepancia: lo mata el éxito de una misión cumplida. Son ahora los más sensatos de los sensatos, Sancho, Sansón Carrasco, el Cura, los que quieren ser "locos".

Y esto me lleva al epílogo de esta incursión: don Quijote es un verdadero vanguardista. Y planteo aquí, contra la pedantería en boga, que "vanguardista" no es fundamentalmente quien sale corriendo adelante, sino quien corriendo al frente hace correr adelante a los demás.

Una y otra vez, a lo largo de esta espléndida novela-comedia que es la obra de Cervantes las personas acceden a la incertidumbre de vivir lo inesperado, ya sea fingiendo ser otras, o siendo, como los galeotes liberados, otros por las circunstancias anárquicas de un capricho de la identidad. Si los Pero Grullos del mundo con su atroz lucidez, castigan al artífice de sus desequilibrios, lo hacen siendo otros por el instante que dura el rapto lúdico. Esa experiencia de desensimismamiento les hará ver que la fantasía es posible. El juego hace a las almas plásticas y vulnerables. Sancho Panza, al final del recorrido, no ha ganado fortuna ("Abre los ojos, deseada patria, y mira que vuelve a ti Sancho Panza tu hijo, si no muy rico, muy bien azotado"), pero el cúmulo de roles lo ha transformado en un ser sensible, capaz de la más dramática y virtuosa empatía.

Emblemáticamente sus últimas, y por lo tanto solemnes palabras en la novela, son las que pronuncia para animar a su amo a vencer la melancolía que a todas luces lo lleva a la muerte, en las cuales se propone culpable del final de la gesta, sin imaginar que justamente este acto es el triunfo más bello del Caballero de la Triste Figura:

"Si es que se muere de pesar de verse vencido, écheme a mí la culpa, diciendo que por haber cinchado yo mal a Rocinante le derribaron..." 